\title{
Hubungan Aktivitas Penggunaan Media Sosial dengan Hasil Belajar Siswa Mata Pelajaran Sosiologi Kelas XI IPS di SMA N 1 Pantai Cermin Kabupaten Solok
}

\author{
Nadia Oktavia ${ }^{1}$, Ike Sylvia ${ }^{2}$ \\ ${ }^{1,2}$ Universitas Negeri Padang \\ Email: oktavianaia076@gmail.com, ikesylvia@fis.unp.ac.id
}

\begin{abstract}
Abstrak
Tingginya aktivitas siswa dalam menggunakan media sosial pada saat proses pembelajaran menyebankan hasil belajar mata pelajaran sosiologi belum maksimal. Penelitian ini memfokuskan pada hubungan aktivitas penggunaan media sosial dengan hasil belajar siswa. Tujuan penelitian ini adalah untuk mengetahui hubungan aktivitas penggunaan media sosial terhadap hasil belajar siswa pada mata pelajaran sosiologi di kelas XI IPS SMA Negeri 1 Pantai Cermin. Penelitian ini merupakan jenis penelitian kuantitatif korelasional. Variabel dalam penelitian ini terdiri dari variabel bebas aktivitas mengakses sosial media dan variabel terikat hasil belajar. Populasi dalam penelitian ini adalah siswa kelas XI di SMA N 1 Pantai Cermin yang berjumlah 85 orang dengan teknik pengambilan sampel menggunakan total sampling. Berdasarkan uji hipotesis menggukan teknik analisis productmoment dapat dilihat bahwa nilai pearson corelation pada masing-masing variabel 0.368 atau berada $0,20-0,399$. Hal ini menunjukkan bahwa corelasi antara variabel $\mathrm{x}$ terhadap y dapat dikatakan lemah pada indikator aktivitas mengakses media sosial aplikasi Facebook, Tiktok, Whatsapp, dan Instagram. Dari hasil observasi didapatkan penggunaan media sosial yang beragam pada kelas XI IPS yang didominasi oleh sosial media Facebook, Instagram, WhatsApp, dan Tiktok.
\end{abstract}

Kata kunci: Hasil Belajar, Penggunaan Sosial Media, Siswa

\section{Abstract}

The high activity of students in using social media during the learning process causes the learning outcomes of sociology subjects to be not optimal. This study focuses on the relationship between the use of social media activities with student learning outcomes. The purpose of this study was to determine the relationship between the use of social media activities on student learning outcomes in sociology subjects in class XI IPS SMA Negeri 1 Pantai Cermin. This research is a type of correlational quantitative research. The variables in this study consisted of the independent variable accessing social media activities and the dependent variable learning outcomes. The population in this study were students of class XI at SMA N 1 Pantai Cermin, amounting to 85 people with the sampling technique using total sampling. Based on the hypothesis test using the product-moment analysis technique, it can be seen that the Pearson correlation value for each variable is 0.368 or is $0.20-0.399$. This shows that the correlation between the variables $x$ to $y$ can be said to be weak on the activity indicators for accessing social media applications such as Facebook, Tiktok, Whatsapp, and Instagram. From the observations, it was found that the use of various social media in class XI IPS was dominated by social media Facebook, Instagram, WhatsApp, and Tiktok.

Keywords: Learning Outcomes, Students, Use of Social Media

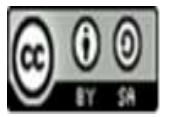




\section{Pendahuluan}

Seiring perubahan zaman, perkembangan teknologi dan informasi mengalami kemajuan yang sangat pesat, ditandai dengan kemajuan pada bidang informasi dan teknologi. Bangsa Indonesia merupakan salah satu bangsa yang ikut terlibat dalam kemajuan media informasi dan teknologi (Ameliola \& Nugraha, 2013). Salah satu perkembangan internet yang paling mencolok dibandingkan dengan layanan lain adalah media sosial. Dengan media sosial orang mengakses internet tidak hanya untuk mencari informasi tetapi juga dapat berkomunikasi (Nurmihasti, 2012).

Media sosial adalah sebuah media yang isinya diciptakan dan didistribusikan melalui sebuah interaksi sosial. Media sosial merupakan sebuah aplikasi yang mengizinkan penggunaannya berinteraksi dan memberikan timbal balik dengan sesama pengguna; membuat, mengedit dan membagikan informasi dalam berbagai bentuk (Selwyn, 2012). Pertumbuhan media sosial selama beberapa tahun terakhir telah membawa perubahan cara pemanfaatan bagi penggunanya dalam dunia pendidikan. Berdasarkan hasil penelitian yang dilakukan oleh Rusdi (2019) menunjukkan bahwa media sosial berpengaruh terhadap hasil belajar siswa.

Dalam bidang pendidikan media sosial mendapatkan dampak yang cukup berarti, dimana pada dasarnya pendidikan merupakan suatu proses komunikasi dan informasi dari pendidik kepada peserta didik yang berisi informasi-informasi pendidikan, yang memiliki unsur-unsur pendidik dan sebagai sumber informasi, media sosial dimanfaat sebagai media penyajian ide gagasan dan materi pendidikan serta peserta didikoitu sendiri (Oetomo \& Priyogutomo, 2004) beberapa bagian unsur ini mendapatkan sentuha media sosial sebagai sarana teknologi informasi termasuk di SMA N 1 Pantai Cermin Kabupaten Solok. Namun tinggiya aktivitas siswa menggunakan media sosial pada saat proses pembelajaran menyebabkan hasil pembelajaran belum maksimal.

SMA N 1 Pantai Cermin adalah satu-satunya SMA yang ada di Kecamatan Pantai Cermin Kabupaten Solok dengan status akreditasi A sejak tahun 2016. Sekolah ini terdiri dari 17 rombel dengan peminatan IPA dan IPS seimbang yang memiliki akses internet di sekolah, dengan sarana dan prasarana yang cukup memadai sebagai penunjang proses belajar siswa. Seiring dengan kebijakan pemerintah pada masa pandemi mulai bulan Maret 2020, sekolah ini memberlakukan pembelajaran online hingga pertengahan semester Juli-Desember 2020. Namun sejak November 2020 hingga saat ini sekolah memberlakukan sistem shift dalam pembelajaran.

Berdasarkan observasi awal peneliti di SMAN 1 Pantai Cermin pada masa pembelajaran daring di era Pandemi Covid-19 guru menggunakan google classroom, whaatApps group, serta pengumpulan tugas ke sekolah bagi siswa yang tidak memiliki akses internet. Guru menggunakan media sosial sebagai media penyampaian informasi dalam proses pembelajaran. Bukan hanya sebagai sarana berbagi informasi dalam proses pembelajaran daring, namun tujuan menggunakan media sosial untuk mencari materi-materi yang berhubungan dengan pembelajaran serta menambah materi yang tidak ada pada buku paket yang cenderung ringkas dalam penjelasannya, serta untuk berdiskusi kelompok antar siswa ataupun dengan guru pada saat pembelajaran secara online berlangsung.

Media sosial berdampak positif bagi proses pembelajaran daring di SMA N 1 Pantai Cermin, namun juga berdampak negatif terhadap siswa seperti adanya siswa yang menyimpang dalam mengakses media sosial secara diam-diam pada saat proses pembelajaran ataupun saat berdiskusi kelompok dari jarak jauh mereka bukan fokus untuk berdiskusi melainkan melakukan hal lain seperti becanda, atau acuh tak acuh dalam diskusi kelompok tersebut sehingga mereka tidak berkonsentrasi dalam diskusi tersebut. 
Pengguaan media sosial yang tidak digunakan dengan semestinya juga berdampak buruk bagi hasil belajar siswa. Media sosial dapat menyita waktu peserta didik dalam proses belajar mengajar sehingga mengakibatkan hasil belajar siswa menurun dalam proses pembelajaran daring pada era Pandemi Covid-19. Proses pembelajaran bisa berjalan dengan baik dan efektif jika media sosial dimanfaatkan dengan semestinya oleh guru dan siswa maka hasil belajar siswa akan menjadi baik, karena hasil belajar baik itu juga dikarenakan oleh proses pembelajaran yang baik serta motivasi belajar dari diri siswa itu sendiri. Sesuai dengan buku penilaian yaitu ada yang nilai tuntas, tuntas dengan remedial dan tidak untas.

Berdasarkan studi pendahuluan yang dilakukan oleh peneliti di SMA N 1 Pantai Cermin, peneliti mendapatkan data siswa di SMA N 1 Pantai Cermin, data dari kelas XI IPS 1, XI IPS 2, XI IPS 3 sebagai berikut:

Tabel 1. Informasi Nilai Siswa Tahun 2019

\begin{tabular}{cccccccc}
\hline \multirow{2}{*}{ No. Kelas } & \multirow{2}{*}{$\begin{array}{c}\text { Jumlah } \\
\text { Siswa }\end{array}$} & \multirow{2}{*}{ KKM } & \multirow{2}{*}{$\begin{array}{c}\text { Nilai Rata- } \\
\text { Rata }\end{array}$} & & & & \multicolumn{2}{c}{ Kategori } \\
\cline { 6 - 7 } & & & & & Tuntas & Tidak Tuntas \\
\hline 1 & XI IPS 1 & 28 & 80 & 89.68 & 28 & N \\
\hline 2 & XI IPS 2 & 28 & 80 & 89.50 & 28 & 0 \\
\hline 3 & XI IPS 3 & 29 & 80 & 87.69 & 27 & 2 \\
\hline
\end{tabular}

Sumber: Admin Tata Usaha SMA N 1 Pantai Cermin

Dari tabel di atas terlihat bahwa hasil belajar siswa tahun 2019 di SMA N 1 Pantai cermin di Kabupaten Solok pada masa pembelajaran sebelum pada era Covid-19 cendrung di atas KKM dengan nilai sangat memuaskan, berdasarkan observasi awal peneliti hal itu dipengaruhi oleh pembelajaran tatap muka tanpa menggunakan media sosial, hal itu berpengaruh terhadap hasil belajar siswa yang cukup memuaskan dan meningkatkan kreatifitas siswa di SMA N 1 Pantai cermin di Kabupaten Solok.

Tabel 2. Informasi Nilai Siswa Tahun 2020

\begin{tabular}{|c|c|c|c|c|c|c|}
\hline \multirow{3}{*}{ No. } & \multirow{3}{*}{ Kelas } & \multirow{3}{*}{$\begin{array}{c}\text { Jumlah } \\
\text { Siswa }\end{array}$} & \multirow{3}{*}{ KKM } & \multirow{3}{*}{$\begin{array}{c}\text { Nilai Rata- } \\
\text { Rata }\end{array}$} & \multicolumn{2}{|c|}{ Kategori } \\
\hline & & & & & Tuntas & Tidak Tuntas \\
\hline & & & & & $\mathrm{N}$ & $\mathrm{N}$ \\
\hline 1 & XI IPS 1 & 28 & 80 & 80.96 & 17 & 11 \\
\hline 2 & XI IPS 2 & 28 & 80 & 80.25 & 21 & 7 \\
\hline 3 & XI IPS 3 & 29 & 80 & 80.14 & 18 & 11 \\
\hline
\end{tabular}

Sumber: Admin Tata Usaha SMA N 1 Pantai Cermin

Dari tabel di atas terlihat bahwa hasil belajar siswa tahun 2020 di SMA N 1 Pantai cermin di Kabupaten Solok pada masa pembelajaran daring di era Covid-19 cendrung hanya batas KKM, berdasarkan observasi awal peneliti hal itu dipengaruhi oleh media sosial membatasi ruang tatap muka antara guru dan siswa. Media sosial dimanfaatkan oleh guru dan siswa sebagai sarana berbagi informasi, materi, dan lain-lain 
Tabel 3. Informasi Demografi Responden $(\mathrm{N}=85)$

\begin{tabular}{llll}
\hline Kategori & Item & Jumlah & \% \\
\hline \multirow{2}{*}{ Kender } & Laki-laki & 38 & 44,70 \\
\cline { 2 - 4 } & Perempuan & 47 & 55,29 \\
& XI IPS 1 & 28 & 28 \\
\cline { 2 - 4 } Pengguna aktif internet & XI IPS 2 & 28 & 28 \\
\cline { 2 - 4 } & XI IPS 3 & 29 & 29 \\
\hline Pengguna aktif media sosial & Ya & 83 & 97,64 \\
\cline { 2 - 4 } & Tidak & 2 & 2,35 \\
\cline { 2 - 4 } & Ya & 80 & 94,11 \\
\cline { 2 - 4 } & Tidak & 5 & 5,80 \\
\hline
\end{tabular}

Sumber: Admin Tata Usaha SMA N 1 Pantai Cermin

Pada penelitian awal ini, 97\% responden mengaku sebagai pengguna internet aktif, 94\% menyatakan aktif menggunakan media sosial. Terkait dengan perangkat yang mereka gunakan untuk mengakses media sosial, hasilnya bahwa smartphone saat ini menjadi perangkat yang paling banyak digunakan oleh peserta didik untuk mengakses media sosial. Sebagian besar peserta didik menggunakan WhatsApp, jumlahnya mencapai 95,96\% responden. Selanjutnya 90,91\% responden menggunakan Facebook, dan 73,74\% responden menggunakan Instagram. Sedangkan pengguna Tiktok sebanyak 57,58\% responden.

Berdasarkan observasi tersebut, sekolah kemudian membuat kebijakan untuk melaksanakan pembelajaran dengan sistem shift dengan persetujuan dari Kepala Daerah. Observasi yang peneliti lakukan pada pembelajaran dengan sistim shift ini, peneliti menemukan fakta ketika pembelajaran sedang berlangsung ada siswa yang bercerita di bangku dengan temannya ketika guru sedang menjelaskan pelajaran di depan kelas. Ada juga siswa yang tidak membuat catatan ketika guru menjelaskan, mereka hanya mendengarkan saja. Ketika guru bertanya apa saja yang telah dijelaskan oleh gurunya mereka hanya terdiam dan terkadang mengatakan lupa. Mereka juga terkadang tidak menyelesaikan tugas yang diberikan oleh gurunya dengan alasan lupa dan gak bisa mengerjakannya karena susah. Hal itu terjadi karena mereka tidak ingin bertanya kepada guru atau teman yang sudah paham tentang tugas yang diberikan. Sulit sekali siswa berupaya untuk mencari berbagai sumber belajar yang dapat mereka akses melalui internet, namun mereka aktif mengupdate media sosialnya.

Salah satu masalah dalam media sosial terkadang memiliki hambatan/kendala dalam akses internet yang kurang memadai, kurangnya interaksi tatap muka memberikan beberapa kecemasan bagi beberapa siswa. Sistem belajar jarak jauh sebenarnya jauh dari sempurna karena menghasilkan siswa atau mahasiswa yang mandiri dalam proses belajar. Dalam sistem tatap muka, seseorang membutuhkan interaksi atau komunikasi langsung dengan guru, interaksi atau komunikasi dengan sumber belajar, dan interaksi atau komunikasi dengan siswa/mahasiswa. Jika dari salah satu hal tersebut tidak terpenuhi, maka hasil yang diperoleh menjadi tidak maksimal dalam pembelajaran. Keberhasilan dalam belajar mandiri sangat dipengaruhi oleh kemampuan dalam mencari informasi oleh siswa itu sendiri.

Proses belajar mengajar bisa berjalan dengan baik dan efektif maka hasil belajar siswa juga akan menjadi baik, karena hasil belajar baik itu juga dikarenakan oleh prose pembelajaran yang baik serta motivasi belajar dari diri siswa itu sendiri. Sesuai dengan buku penilaian yaitu ada yang nilai tuntas, tuntas dengan remedial dan tidak tuntas. Untuk meningkatkan hasil belajar tersebut guru sosiologi memberikan tugas berupa tugas rumah yang bertujuan agar siswa dapat mempersiapkan diri untuk proses pembelajaran yang akan dilakukan di sekolah. Jika siswa mengerjakan tugas maka siswa tersebut akan bisa menjawab pertanyaan

Jurnal Sikola: Jurnal Kajian Pendidikan dan Pembelajaran Vol. 3, No. 2, Th. 2021 
yang diberikan oleh guru pada saat proses pembelajaran. Tugas rumah yang diberikan kepada siswa bermacam-macam diantaranya, membuat pertanyaan atau menjawab pertanyaan, membuat ringkasan materi yang akan dipelajari dan lain-lain.

Berdasarkan uraian di atas maka penulis tertarik untuk melakukan penelitian yang mengenai "Hubungan Aktivitas Penggunaan Media Sosial Terhadap Hasil Belajar Siswa di Kelas XI IPS SMAN 1 Pantai Cermin”.

\section{Metode Penelitian}

Pendekatan dalam penelitian ini yaitu penelitian kuantitatif. Penelitian ini merupakan jenis penelitian kuantitatif korelasional. Variabel penelitian yaitu variabel aktivitas mengakses sosial media dengan hasil belajar. Populasi dalam penelitian ini adalah seluruh siswa kelas XI IPS di SMA N 1 Pantai Cermin. Teknik pengambilan sampel menggunakan total sampling. Teknik pengumpulan data dengan memberikan kuisioner (angket) kepada siswa dengan jumlah sampel sebanyak 85 responden. Teknik analisa data yang digunakan dalam penelitian ini adalah analisis deskriptif kuantitatif, uji prasyarat analisis dan uji hipotesis menggunakan teknik analisis product moment.

\section{Hasil Penelitian}

Populasi pada penelitian ini adalah siswa kelas XI IPS di SMA N 1 Pantai Cermin. Peneliti menjadikan seluruh siswa kelas XI IPS sebagai sampel (total sampling) karena jumlahnya tidak melebihi dari 100 subjek. Berdasarkan kuesioner yang dibagikan tidak ada satu pun siswa kelas XI IPS SMA N 1 Pantai cermin yang menolak menerima angket, sehingga sampel yang direncanakan 85 orang siswa semuanya mengisi dengan lengkap. Hingga batas akhir pengumpulan data, angket yang diterima kembali 85 angket.

\section{Analisis Deskriptif Kuantitatif}

Berdasarkan tabel dibawah ini menunjukkan bahwa responden yang paling dominan pernyataan aktivitas mengakses sosial media adalah minat dalam mengakses sosial media dengan nilai mean 4.27. Sedangkan pernyataan yang paling rendah jawaban responden adalah pernyataan motivasi internal dalam mengakses sosial media dengan nilai rata-rata 4.00.

Tabel 4. Analisis Deskriptif Kuantitatif Berdasarkan Aktivitas Mengakses Sosial Media

\begin{tabular}{llcccccc}
\hline No & \multicolumn{1}{c}{ Pernyataan } & SS & S & N & TS & STS Mean \\
\hline 1 & Motivasi internal dalam mengakses sosial media & 13 & 59 & 13 & 0 & 0 & 4 \\
\hline 2 & Motivasi eksternal dalam mengakses sosial media & 11 & 64 & 10 & 0 & 0 & 4.01 \\
\hline 3 & Durasi dalam mengakses sosial media & 19 & 54 & 10 & 0 & 0 & 4.08 \\
\hline 4 & Frekuensi dalam mengakses sosial media & 22 & 51 & 12 & 0 & 0 & 4.12 \\
\hline 5 & Arah sikap sosial media ketika belajar & 16 & 64 & 5 & 0 & 0 & 4.13 \\
\hline 6 & Minat dalam mengakses sosial media. & 7 & 48 & 30 & 0 & 0 & 4.27 \\
\hline 7 & Target yang ingin dicapai dengan mengakses sosial media. & 13 & 59 & 13 & 0 & 0 & 4 \\
\hline 8 & Keinginan dalam mengakses sosial media. & 13 & 39 & 33 & 0 & 0 & 4.24 \\
\hline
\end{tabular}

Sumber : Data Primer (2021)

Berdasarkan tabel dibawah ini menunjukkan bahwa responden yang paling dominan pernyataan aplikasi facebook adalah mengirim pesan kepada teman dengan nilai mean 4.19. 
sedangkan pernyataan yang paling rendah jawaban responden adalah pernyataan mengunggah foto dengan nilai mean 3.94 .

Tabel 5. Analisis Deskriptif Kuantitatif Berdasarkan Aplikasi Facebook

\begin{tabular}{|c|c|c|c|c|c|c|c|}
\hline No & Pernyataan & SS & $\mathbf{S}$ & $\mathbf{N}$ & TS & STS & Mean \\
\hline 1 & Memberikan komentar & 15 & 69 & 1 & 0 & 0 & 4.16 \\
\hline 2 & Mengunggah foto & 14 & 52 & 19 & 0 & 0 & 3.94 \\
\hline 3 & Mengupdate status & 9 & 62 & 14 & 0 & 0 & 3.94 \\
\hline 4 & Memberi "likes" atau tanda suka ke postingan teman & 18 & 58 & 9 & 0 & 0 & 4.11 \\
\hline 5 & Melihat jumlah likes atau tanda suka dari teman & 12 & 70 & 3 & 0 & 0 & 4.11 \\
\hline & Share link melalui facebook & 0 & 84 & 1 & 0 & 0 & 3.99 \\
\hline 7 & Mengirim pesan kepada Teman & 22 & 57 & 6 & 0 & 0 & 4.19 \\
\hline & Mencari teman & 4 & 80 & 1 & 0 & 0 & 4.04 \\
\hline
\end{tabular}

Sumber: Data Primer (2021)

Tabel dibawah ini menunjukkan bahwa responden yang paling dominan pernyataan aplikasi tiktok adalah melihat pembaruan teman dengan nilai mean 4.20. Sedangkan pernyataan yang paling rendah jawaban responden adalah pernyataan mengecek jumlah followers atau pengikut dengan nilai mean 4.06 .

Tabel 6. Analisis Deskriptif Kuantitatif Berdasarkan Aplikasi Tiktok

\begin{tabular}{clcccccc}
\hline No & Pernyataan & SS & S & N & \multicolumn{2}{c}{ TS } & STS Mean \\
\hline 1 & Mengunggah video & 15 & 62 & 8 & 0 & 0 & 4.08 \\
\hline 2 & Mengecek jumlah followers atau pengikut & 13 & 64 & 8 & 0 & 0 & 4.06 \\
\hline 3 & Mengikuti teman (following) & 13 & 67 & 5 & 0 & 0 & 4.09 \\
\hline 4 & Melihat pembaruan teman & 22 & 58 & 5 & 0 & 0 & 4.2 \\
\hline 5 & Melihat notifikasi & 17 & 66 & 2 & 0 & 0 & 4.18 \\
\hline
\end{tabular}

Sumber : Data Primer (2021)

Tabel 7 dibawah ini menunjukkan bahwa responden yang paling dominan pernyataan aplikasi whatshapp adalah melihat pembaruan status teman (recent update) teman dengan nilai mean 4.29. Sedangkan pernyataan yang paling rendah jawaban responden adalah pernyataan chatting atau mengirim pesan dengan nilai mean 4.04.

Tabel 7. Analisis Deskriptif Kuantitatif Berdasarkan Aplikasi WhatsApp

\begin{tabular}{|c|c|c|c|c|c|c|c|}
\hline No & Pernyataan & SS & $\mathbf{S}$ & $\mathbf{N}$ & TS & STS & Mean \\
\hline 1 & Invite & 21 & 61 & 3 & 0 & 0 & 4.21 \\
\hline 2 & Chatting atau mengirim Pesan & 11 & 66 & 8 & 0 & 0 & 4.04 \\
\hline 3 & Melihat pembaruan status teman (Recent Update) teman & 34 & 42 & 9 & 0 & 0 & 4.29 \\
\hline 4 & Mengirim dan menerima file & 17 & 60 & 8 & 0 & 0 & 4.11 \\
\hline 5 & Mengirim dan menerima Foto & 18 & 56 & 11 & 0 & 0 & 4.08 \\
\hline
\end{tabular}

Sumber: Data Primer (2021)

Selanjutnya pada tabel dibawah ini menunjukkan bahwa responden yang paling dominan pernyataan aplikasi instagram adalah mencari akun teman melalui search engine dengan nilai mean 4.11. Sedangkan pernyataan yang paling rendah jawaban responden adalah pernyataan melihat jumlah follower dan following dengan nilai mean 4.00. 
Tabel 8. Analisis Deskriptif Kuantitatif Berdasarkan Aplikasi Instagram

\begin{tabular}{clcccccc}
\hline No & Pernyataan & SS & S & N & TS & STS Mean \\
\hline 1 & Memposting foto & 12 & 65 & 8 & 0 & 0 & 4.05 \\
\hline 2 & Memberi like dan komentar & 15 & 62 & 15 & 0 & 0 & 4.08 \\
\hline 3 & pada postingan teman & 12 & 65 & 8 & 0 & 0 & 4.05 \\
\hline 4 & Melihat jumlah Follower dan Following & 3 & 79 & 3 & 0 & 0 & 4 \\
\hline 5 & Mengirim pesan & 3 & 79 & 3 & 0 & 0 & 4 \\
\hline 6 & Melihat tautan dan Pembaruan & 11 & 69 & 5 & 0 & 0 & 4.07 \\
\hline 7 & Mencari akun teman melalui search engine & 16 & 62 & 7 & 0 & 0 & 4.11 \\
\hline
\end{tabular}

Sumber : Data Primer (2021)

\section{Uji Normalitas}

Uji normalitas adalah sebuah uji yang dilakukan dengan tujuan untuk menilai sebaran data pada sebuah kelompok data atau variabel, apakah sebaran data tersebut berdistribusi normal ataukah tidak. Tabel dibawah ini memperlihatkan bahwa nilai asymp sign pada masing-masing variabel $0.055>0.05$. Hal ini menunjukkan bahwa data terdistribusi normal.

\section{Tabel 9. Tabel Uji Normalitas}

\begin{tabular}{|c|c|c|}
\hline \multicolumn{3}{|c|}{ One-Sample Kolmogorov-Smirnov Test } \\
\hline \multicolumn{3}{|c|}{ Unstandardized Residual } \\
\hline $\mathrm{N}$ & & 85 \\
\hline \multirow{2}{*}{$\begin{array}{l}\text { Normal } \\
\text { Parameters }^{\mathrm{a}}\end{array}$} & Mean & 0 \\
\hline & Std. Deviation & 2.49977016 \\
\hline \multirow{3}{*}{$\begin{array}{l}\text { Most Extreme } \\
\text { Differences }\end{array}$} & Absolute & 0.187 \\
\hline & Positive & 0.187 \\
\hline & Negative & -0.098 \\
\hline \multicolumn{2}{|c|}{ Kolmogorov-Smirnov Z } & 1.726 \\
\hline \multicolumn{2}{|c|}{ Asymp. Sig. (2-tailed) } & 0.055 \\
\hline
\end{tabular}

Sumber: Data Primer (2021)

\section{Uji Linieritas}

Berdasarkan tabel dibawah ini dapat dilihat bahwa nilai linearitas $<(0.05)$ dan hal ini menunjukkan bahwa tidak terjadi gejala linearitas.

\section{Tabel 10. Uji Linearitas}

\begin{tabular}{|c|c|c|c|c|c|c|c|}
\hline \multicolumn{8}{|c|}{ ANOVA Table } \\
\hline & & & $\begin{array}{l}\text { Sum of } \\
\text { Squares }\end{array}$ & df & $\begin{array}{l}\text { Mean } \\
\text { Square }\end{array}$ & $\mathrm{F}$ & Sig. \\
\hline \multirow{5}{*}{$\begin{array}{l}\mathrm{Y}^{*} \\
\mathrm{X}\end{array}$} & \multirow{3}{*}{ Between Groups } & (Combined) & 207.836 & 27 & 7.698 & 1.099 & 0.37 \\
\hline & & Linearity & 82.108 & 1 & 82.108 & 11.725 & 0 \\
\hline & & Deviation from Linearity & 125.727 & 26 & 4.836 & 0.691 & 0.85 \\
\hline & Within Groups & & 399.176 & 57 & 7.003 & & \\
\hline & Total & & 607.012 & 84 & & & \\
\hline
\end{tabular}

Sumber: Data Primer (2021) 
Pada tabel uji hipotesis dapat dilihat bahwa nilai pearson corelation pada masing-masing variabel 0.368 atau berada $0,20-0,399$. Hal ini menunjukkan bahwa korelasi antara variabel $\mathrm{X}$ terhadap Y dapat dikatakan lemah.

Tabel 11. Uji Hipotesis

\begin{tabular}{|c|c|c|c|}
\hline \multicolumn{4}{|c|}{ Correlations } \\
\hline & & $\mathrm{X}$ & $\mathrm{Y}$ \\
\hline \multirow{3}{*}{$\mathrm{X}$} & Pearson Correlation & 1 & $.368^{*}$ \\
\hline & Sig. (2-tailed) & & 0.001 \\
\hline & $\mathrm{N}$ & 85 & 85 \\
\hline \multirow{3}{*}{ Y } & Pearson Correlation & $.368^{* *}$ & 1 \\
\hline & Sig. (2-tailed) & 0.001 & \\
\hline & $\mathrm{N}$ & 85 & 85 \\
\hline
\end{tabular}

\section{Pembahasan}

Berdasarkan uji hipotesis dapat dilihat bahwa nilai pearson corelation pada masingmasing variabel 0.368 atau berada 0,20-0,399. Hal ini menunjukkan bahwa korelasi antara variabel $\mathrm{X}$ terhadap $\mathrm{Y}$ dapat dikatakan lemah. Kemajuan Teknologi Informasi dan Komunikasi membawa pengaruh yang dengan kemajuan teknologi, kehadiran sosial media juga turut berkembang, dan diharapkan mampu menjawab kebutuhan masyarakat khususnya siswa. Media sosial diharapkan tidak hanya mampu mengubah cara pandang dan perilaku dalam komunikasi antar pertemanan saja tetapi juga mampu meningkatkan kualitas hidup siswa baik dalam hal perilaku maupun kualitas belajar. Penggunaan media sosial di SMA N 1 Pantai Cermin cukup tinggi dan beragam. Dari hasil observasi didapatkan penggunaan media sosial yang beragam pada kelas XI IPS yang didominasi oleh sosial media Facebook, Instagram, Whatsapp, dan Tiktok.

Hasil belajar siswa pada saat Pembelajaran Sosiologi di SMA N 1 Pantai Cermin berdasarkan pengamatan pada saat peneliti melakukan penelitian belum baik. Berdasarkan hasil observasi, kurang efektifnya pembelajaran mata pelajaran sosiologi disebabkan karena tingginya aktivitas siswa menggunakan media sosial yang tidak menyangkut pada konten pembelajaran. Selain itu permasalahan lain seperti siswa tidak mau mengumpulkan tugas tepat waktu, cenderung menumpuk tugas dan tidak mengindahkan guru mengajar baik menggunakan google classroom maupun tatap muka dalam bentuk shift (bergantian selama pandemic). Kondisi ini membuat pembelajaran sosiologi kurang produktif dan tingginya aktivitas siswa menggunakan sosial media tidak untuk mengakses konten pembelajaran membuat pembelajaran yang kurang kondusif.

\section{Kesimpulan}

Berdasarkan hasil penelitian, analisis data dan pembahasan, maka diambil simpulan berdasarkan uji hipotesis dapat dilihat bahwa nilai pearson corelation pada masing masing variabel 0.368 atau berada $0,20-0,399$. Hal ini menunjukkan bahwa korelasi antara variabel X terhadap Y dapat dikatakan lemah. Kemajuan Teknologi Informasi dan Komunikasi membawa pengaruh yang Dengan kemajuan teknologi, kehadiran sosial media juga turut berkembang, dan diharapkan mampu menjawab kebutuhan masyarakat khususnya siswa. Media sosial diharapkan tidak hanya mampu mengubah cara pandang dan perilaku dalam komunikasi antar pertemanan saja tetapi juga mampu meningkatkan kualitas hidup siswa

Jurnal Sikola: Jurnal Kajian Pendidikan dan Pembelajaran Vol. 3, No. 2, Th. 2021 
baik dalam hal perilaku maupun kualitas belajar. Penggunaan media sosial di SMA N 1 Pantai Cermin cukup tinggi dan beragam. Dari hasil observasi didapatkan penggunaan media sosial yang beragam pada kelas XI IPS yang didominasi oleh sosial media Facebook, Instagram, WhatsApp, dan Tiktok.

\section{Daftar Pustaka}

Ameliola, S.N. (2013). Perkembangan Media Informasi Dan Teknologi Terhadap Anak Dalam Era Globalisasi. Malang: Universitas Brawijaya.

Arif, Rohmadi. (2016). Tips Produktif Ber-social Media. Jakarta: Elek MediaKomputindo.

Arikunto, S. (2009). Prosedur Penelitian Suatu Pendekatan Praktik. Edisi Revisi 6. Jakarta: Rineka Cipta.

Dela, Agustiah. (2020). Dampak Penggunaan Media Sosial Terhadap Perilaku Belajar Siswa

Esto, E. (2019). Pengaruh Penggunaan Media Sosial Terhadap Prestasi Belajar Peserta Didik Jurusan IPA SMAN I Talibura.

Masfufah, M. (2015). Hubungan Keaktifan Penggunaan Media Sosial Terhadap Hasil Belajar Fisika Siswa Kelas X dan XI IPA di SMA Negeri 5 Banjarmasin.

Meyrowitz. (1999). Understanding of Media. Et Cetera. Mosco, C. F. (n.d.). Marx and the Political Economy Of The Media. Leiden

Mudjiono, M. (2013). Belajar Dan Pembelajaran. Jakarta: Rineka Cipta.

Nasrullah, R. (2016). Media Sosial: Perspektif Komunikasi, Budaya, dan Sosioteknologi. Bandung: Simbiosa Rekatama Media

Nasution, N. (2013). Berbagai Pendekata Dalam Proses Belajar Mengajar. Jakarta: Bumi Aksara

Oetomo, B.S.D \& Jarot, P. (2004). Kajian Terhadap Model e-Media Dalam Pembangunan Sistem e-Education

Rusdi, R. (2019). Pengaruh Pembelajaran Berbasis Masalah Menggunakan Media Sosial ELearning Terhadap Hasil Belajar Siswa Sekolah Menengah Pada Sistem Pencernaan.

Selwyn, Neil. (2012). Education and Technology: Key Issues.

Sith, S. (2009). Dasar-Dasar Psikologi Kualitatif. Yogyakarta: Pustaka Pelajar.

Sugiyono, S. (2010). Metode Penelitian Pendidikan. Bandung: Alfabeta.

Sukmadinata, S. (2004). Belajar dan Pembelajaran. Bandung: Remaja Rosdakarya.

Sundawati. K. (2018). Penggunaan Media Sosial Instagram Dalam Upaya Meningkatkan Hasil Belajar Dan Motivasi Siswa Kelas XI Pada Materi Sel. Skripsi. Unpas.

Suprijono, S. (2009). Cooperative Learning. Yogyakarta: Pustaka Pelajar.

Van Dijck, J. (2013). The Culture of Connectivity: A Critical History of Social. Media. UK: Oxford University Press.

Vista, E. (2019). Hubungan Penggunaan Media Sosial Dengan Prestasi Akademik Pelajar Kelas XI di SMA Negeri 9 Manado.

Yata, Y. (2020). Pengaruh Penggunaan Jejaring Sosial Geschool Terhadap Minat Belajar Siswa di SMP Negeri 11 Padang. 